\title{
Assessment of virtual towers performed with scanning wind lidars and Ka-band radars during the XPIA experiment
}

\author{
Mithu Debnath ${ }^{1}$, Giacomo Valerio Iungo ${ }^{1}$, W. Alan Brewer ${ }^{2}$, Aditya Choukulkar ${ }^{2}$, Ruben Delgado ${ }^{3}$, Scott Gunter $^{4}$, \\ Julie K. Lundquist ${ }^{5,6}$, John L. Schroeder ${ }^{7}$, James M. Wilczak ${ }^{2}$, and Daniel Wolfe ${ }^{8}$ \\ ${ }^{1}$ Wind Fluids and Experiments (WindFluX) Laboratory, Mechanical Engineering Department, \\ The University of Texas at Dallas, Richardson, TX, USA \\ ${ }^{2}$ National Oceanic and Atmospheric Administration, Earth Sciences Research Laboratory, Boulder, CO, USA \\ ${ }^{3}$ Atmospheric Physics Department, University of Maryland Baltimore County, Baltimore, MD, USA \\ ${ }^{4}$ Department of Earth and Space Sciences, Columbus State University, Columbus, GA, USA \\ ${ }^{5}$ National Renewable Energy Laboratory, Golden, CO, USA \\ ${ }^{6}$ Department of Atmospheric and Oceanic Sciences, University of Colorado at Boulder, Boulder, CO, USA \\ ${ }^{7}$ Department of Geosciences, Texas Tech University, Lubbock, TX, USA \\ ${ }^{8}$ Physical Sciences Division, National Oceanic and Atmospheric Administration, Boulder, CO, USA
}

Correspondence to: Giacomo Valerio Iungo (valerio.iungo@utdallas.edu)

Received: 1 October 2016 - Discussion started: 14 October 2016

Revised: 1 March 2017 - Accepted: 7 March 2017 - Published: 29 March 2017

\begin{abstract}
During the eXperimental Planetary boundary layer Instrumentation Assessment (XPIA) campaign, which was carried out at the Boulder Atmospheric Observatory (BAO) in spring 2015, multiple-Doppler scanning strategies were carried out with scanning wind lidars and $\mathrm{Ka}$ band radars. Specifically, step-stare measurements were collected simultaneously with three scanning Doppler lidars, while two scanning Ka-band radars carried out simultaneous range height indicator (RHI) scans. The XPIA experiment provided the unique opportunity to compare directly virtual-tower measurements performed simultaneously with Ka-band radars and Doppler wind lidars. Furthermore, multiple-Doppler measurements were assessed against sonic anemometer data acquired from the meteorological tower (met-tower) present at the BAO site and a lidar wind profiler. This survey shows that - despite the different technologies, measurement volumes and sampling periods used for the lidar and radar measurements - a very good accuracy is achieved for both remote-sensing techniques for probing horizontal wind speed and wind direction with the virtual-tower scanning technique.
\end{abstract}

\section{Introduction}

The increasing need of monitoring the atmospheric boundary layer for a broad range of technological and scientific pursuits - such as for meteorology (Banta et al., 2002; Calhoun et al., 2006; Emeis et al., 2007; Horanyi et al., 2015; Vanderwende et al., 2015; Bonin et al., 2015), renewable energy (Thresher et al., 2008; Jones and Bouamane, 2011; Iungo et al., 2013; Aitken et al., 2014; Iungo, 2016) and air traffic management (George and Yang, 2012; Smalikho and Banakh, 2015) - has led to a rapid development of remotesensing measurement techniques, such as wind lidars (Courtney et al., 2008; Cariou, 2015; Simley and Pao, 2012; Iungo and Porté-Agel, 2013, 2014) and radars (Farnet and Stevens, 1990; O'Hora and Bech, 2007; Hirth and Schroeder, 2013; Hirth et al., 2015). Compared to classical meteorological towers, remote-sensing instruments allow easier deployment, enhanced capability of varying deployment locations and potentially lower costs.

A Doppler-based remote-sensing instrument allows measurements of the wind velocity component parallel to the direction of the emitted wave source, e.g., a laser beam for a lidar or radio waves for a radar. The measured wind velocity, which is referred to as radial or line-of-sight velocity, is 
proportional to the Doppler shift on the backscattered signal generated by the aerosol suspended in the atmosphere (Pena et al., 2013). Measurements of multiple velocity components with a single lidar or radar have been typically performed by sequentially sensing different locations of a measurement volume, and assuming flow homogeneity within the measurement volume. This constraint entails limitations on the size of the measurement volume and applicability of these scanning strategies in the presence of significant flow heterogeneity, such as for measurements over complex terrain (Bingöl et al., 2009) and wind turbine wakes (Lundquist et al., 2015).

To overcome limitations connected with multiplecomponent velocity measurements performed with a single instrument, multiple-Doppler scanning strategies have been explored, which require the simultaneous availability of multiple instruments (Newsom et al., 2005; Mikkelsen et al., 2008; Mann et al., 2009; Carbajo-Fuertes et al., 2014; Debnath et al., 2017; Choukulkar et al., 2017). Multiple-Doppler scans consist of probing the wind velocity field at a specific location with various non-parallel line-of-sight velocities in order to characterize the 3-D nature of the atmospheric boundary layer wind field, such as in the presence of wind shear, veer or wakes produced by upwind obstacles (e.g., wind turbines, buildings, topography), or stratified wind turbulence (Segalini and Arnqvist, 2015). The number of independent non-parallel line-of-sight velocities should be equal to or larger than the number of required velocity components (Newsom et al., 2008; Hill et al., 2010; Carbajo-Fuertes et al., 2014). For a specific site, at each measurement point it is possible to optimize azimuthal and elevation angles of the various line-of-sight directions in order to minimize the error in the retrieval of the three Cartesian velocity components (Debnath et al., 2017). It is noteworthy that the accuracy of the retrieved velocity components is a function not only of the experimental setup but also of the accuracy of the individual instruments. Accuracy in the retrieval of the three wind velocity components is a function of the norm of a matrix including trigonometric functions of elevation and azimuthal angles of the measured line-of-sight velocities (Debnath et al., 2017).

The virtual-tower measurements presented in this paper are part of the eXperimental Planetary boundary layer Instrument Assessment (XPIA) field study, which was funded by the U.S. Department of Energy within the Atmosphere to Electrons (A2e) program to estimate accuracy and capabilities of various remote-sensing techniques for the characterization of complex atmospheric flows in and near wind farms. The XPIA experiment was carried out at the National Oceanic and Atmospheric Administration (NOAA), Boulder Atmospheric Observatory (BAO), near Erie, Colorado, for the period 2 March-31 May 2015. An overview of the field campaign is provided in Lundquist et al. (2016), while a detailed analysis of several multiple-Doppler scanning strategies performed with scanning lidars was provided in Choukulkar et al. (2017), and vertical profiles of the three wind velocity components performed with triple RHI scans were presented in Debnath et al. (2017).

The XPIA experiment provided the unique opportunity of having available two Ka-band radars and three scanning wind lidars with the capability of performing multipleDoppler measurements. To the authors' knowledge, this is the first time that virtual towers performed with Ka-band radars and scanning lidars are analyzed through a direct intercomparison. Furthermore, validation of the multipleDoppler measurements was performed against wind velocity data acquired from sonic anemometers, which were installed throughout the height of the meteorological tower (met-tower) present at the BAO site, and a lidar profiler as well.

The remainder of the paper is organized as follows: a description of the instruments deployed for this experiment is provided in Sect. 2. The data retrieval and assessment of the horizontal wind speed and wind direction from dualDoppler RHI scans performed with two Ka-band radars are described in Sect. 3, while a similar survey is then performed for the triple-Doppler step-stare scans carried out with three scanning lidars (Sect. 4). Subsequently, an intercomparison between lidar and radar virtual-tower measurements is described in Sect. 5. Finally, concluding remarks are reported in Sect. 6.

\section{Experimental setup and measurement procedures}

The instrumentation deployed for the XPIA experiment comprised sonic anemometers installed over the BAO met-tower, profiling lidars, radiosonde launches, microwave radiometers and two scanning Ka-band radars. Moreover, five scanning Doppler wind lidars were deployed to explore novel scanning strategies for the characterization of atmospheric boundary layer flows. The multiple-Doppler measurements performed with three scanning wind lidars and two scanning Ka-band radars, which is the focus of this paper, represent one task of a broader test matrix. More details about the XPIA campaign can be found in Lundquist et al. (2016). Virtual-tower measurements over the lidar supersite location (Fig. 1) were performed from 19:00 UTC on 24 March 2015 until 23:00 UTC on 31 March 2015. Wind data from one lidar were not available for the period 27-28 March 2015 due to a connectivity technical issue. The data set presented in this paper is the result of a quality control process, which is a function of aerosol condition and carrier-to-noise ratio of the measured line-of-site velocities. The presented wind data are particularly valuable for assessment purposes due to the broad variability that occurred both in wind speed, from 0 up to $20 \mathrm{~m} \mathrm{~s}^{-1}$, and wind direction, which varied through the full circle of the wind rose

The BAO met-tower was built in 1977 to investigate the planetary boundary layer (Kaimal and Gaynor, 1983). This 


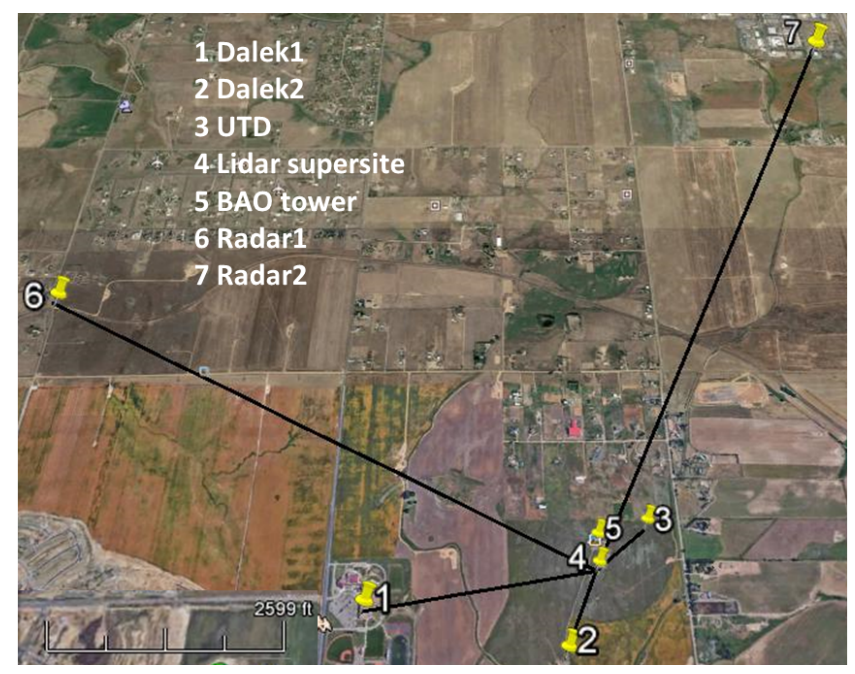

Figure 1. Map of the setup for the virtual-tower measurements performed over the lidar supersite location during the XPIA experiment.

$300 \mathrm{~m}$ tall tower has three legs spaced $3 \mathrm{~m}$ apart, and it is instrumented with temperature and relative humidity sensors at 10,100 and $300 \mathrm{~m}$ above ground level (a.g.l.), while 12 CSAT3 3-D sonic anemometers by Campbell Scientific were installed at 50,100, 150, 200, 250 and $300 \mathrm{~m}$ a.g.l. Six anemometers were installed on booms pointing $\mathrm{NW}\left(334^{\circ}\right)$, which are denoted as NW sonic anemometers, while six other anemometers were installed on SE booms $\left(154^{\circ}\right)$, denoted as SE sonic anemometers. Most of the booms were $4.3 \mathrm{~m}$ long, while at the $250 \mathrm{~m}$ level the SE boom was $3.3 \mathrm{~m}$ long. The sonic anemometers collected data with a sampling frequency of $20 \mathrm{~Hz}$, which were then tilt-corrected following the method proposed in Wilczak et al. (2001). The sonic anemometers were calibrated for the XPIA experiment by Campbell Scientific, with measurement resolution (maximum offset error) of $0.1 \mathrm{~cm} \mathrm{~s}^{-1}\left(8 \mathrm{~cm} \mathrm{~s}^{-1}\right)$ for the horizontal wind speed and $0.05 \mathrm{~cm} \mathrm{~s}^{-1}\left(4 \mathrm{~cm} \mathrm{~s}^{-1}\right)$ for the vertical velocity. It is noteworthy that the sonic anemometers can experience wake effects produced from the met-tower for specific wind directions, i.e., between 111 and $197^{\circ}$ for the NW anemometers, and between 299 and $20^{\circ}$ for the SE anemometers (see McCaffrey et al. (2017) for a more detailed discussion).

Vertical profiles of the three velocity components were performed with the WLS-16 Leosphere Windcube Offshore 8.66 profiling lidar, which is denoted as V2 lidar and has an absolute mean deviation smaller than $0.1 \mathrm{~m} \mathrm{~s}^{-1}$ in wind speed and smaller than $2^{\circ}$ in wind direction. Wind velocity measurements were carried out with the Doppler beam-swinging (DBS) technique (Courtney et al., 2008; Rao et al., 2008) with an elevation angle from vertical of $28^{\circ}$, with a sampling frequency of $1 \mathrm{~Hz}$ and with the range gates centered at 11 vertical heights $(40,50,60,80,100,120,140$,
$150,160,180,200 \mathrm{~m})$. The profiler lidar was deployed at the location referred to as the lidar supersite (Fig. 1), whose GPS coordinates are reported in Table 1.

Two Texas Tech University Ka-band ( $8.6 \mathrm{~mm}$ wavelength) mobile Doppler radars (Hirth and Schroeder, 2013; Hirth et al., 2015; Gunter et al., 2015) were deployed during XPIA. These Ka-band radars were designed to operate in a variety of weather conditions, including precipitation and clear air. As for most radars, data quality and maximum range are typically greatest during periods of precipitation. In such environments, the maximum range of data can often exceed $20 \mathrm{~km}$ (depending on the employed scanning parameters for a given experiment). Data quality and maximum range tend to be reduced in clear-air conditions, but the magnitude of the reduction is highly dependent upon the concentration of clear-air scatters (e.g., dust, insects). Typical ranges in clear air can vary between 3 and $10 \mathrm{~km}$. Late spring, summer and early fall typically provide the best clear-air environments, with biological scatterers being limited during the remaining portions of the year. The accuracy of the dualDoppler virtual towers from radar data has been shown to be fairly consistent across different atmospheric conditions above approximately $50 \mathrm{~m}$ a.g.l. (Gunter et al., 2015). Below this level, dual-Doppler wind speeds tended to be slightly overestimated in heavy precipitation (Gunter et al., 2015). During the XPIA experiment, the Ka-band radars were on site for 30 days. Atmospheric conditions allowed for quality dual-Doppler data collection on 17 days. Data set lengths were largely dependent upon data quality and project objectives. During this time, the following radar scanning parameters were employed: pulse repetition frequency of $15 \mathrm{kHz}$, pulse width of $20 \mu \mathrm{m} \mathrm{s}$ and range resolution of $15 \mathrm{~m}$. Radar 1 (radar 2) was deployed $3.192 \mathrm{~km}(3.9 \mathrm{~km})$ northwest (north) of the BAO tower (Fig. 1). Considering the $0.33^{\circ}$ half-power beam width of the radars, these distances yielded an azimuthal resolution of $18 \mathrm{~m}(22.5 \mathrm{~m})$ for radar 1 (radar 2) at the BAO tower location. Simultaneous RHI scans were performed by focusing both radars over the lidar supersite location by setting the radar azimuthal angles reported in Table 1 , sampling rate equal to $5 \mathrm{~Hz}$ and sampling period of $3.3 \mathrm{~s}$. For the 25 March 2015 data set, virtual-tower data were collected at the onset of precipitation and persisted for $113 \mathrm{~min}$ before switching scanning strategies to accomplish additional objectives. After quality control, analysis of the radar measurements, wind data from the two Ka-band radars for the period 13:20 to 15:07 UTC on 25 March and for heights ranging from 10 to $490 \mathrm{~m}$ height with $20 \mathrm{~m}$ interval were available for this particular study.

Three Leosphere Windcube 200S scanning Doppler wind lidars (University of Texas at Dallas (UTD), NOAA Dalek 1, NOAA Dalek 2) were deployed for this experiment. Wind measurements were performed by means of eye-safe laser with a pulse energy of $0.1 \mathrm{~mJ}$, a wavelength of $1.54 \mu \mathrm{m}$ and a pulse length of $200 \mathrm{~ns}$. Measurements were acquired by using an accumulation time of $0.5 \mathrm{~s}$ and gate length of $50 \mathrm{~m}$. Loca- 
Table 1. GPS locations of the three scanning Doppler wind lidars, wind lidar profiler, Ka-band radars and BAO tower.

\begin{tabular}{lllrrr}
\hline & Longitude & Latitude & Elevation & $\begin{array}{r}\text { Distance } \\
(\mathrm{m})\end{array}$ & $\begin{array}{r}\text { Azimuth } \\
\text { angle }\left(^{\circ}\right)\end{array}$ \\
\hline UTD & $105^{\circ} 00^{\prime} 03.99^{\prime \prime} \mathrm{W}$ & $40^{\circ} 03^{\prime} 02.32^{\prime \prime} \mathrm{N}$ & $1578 \mathrm{~m}$ & 322 & 234.93 \\
Dalek 1 & $105^{\circ} 00^{\prime} 55.64^{\prime \prime} \mathrm{W}$ & $40^{\circ} 02^{\prime} 51.75^{\prime \prime} \mathrm{N}$ & $1578 \mathrm{~m}$ & 985 & 85.95 \\
Dalek 2 & $105^{\circ} 00^{\prime} 20.65^{\prime \prime} \mathrm{W}$ & $40^{\circ} 02^{\prime} 43.09^{\prime \prime} \mathrm{N}$ & $1585 \mathrm{~m}$ & 422 & 29.7 \\
BAO tower & $105^{\circ} 00^{\prime} 13.82^{\prime \prime} \mathrm{W}$ & $40^{\circ} 02^{\prime} 00.13^{\prime \prime} \mathrm{N}$ & $1579 \mathrm{~m}$ & 134 & 181 \\
Ka-band radar 1 & $105^{\circ} 02^{\prime} 13.85^{\prime \prime} \mathrm{W}$ & $40^{\circ} 03^{\prime} 43.70^{\prime \prime} \mathrm{N}$ & $1548 \mathrm{~m}$ & 3192 & 118 \\
Ka-band radar 2 & $104^{\circ} 59^{\prime} 2.98^{\prime \prime} \mathrm{W}$ & $40^{\circ} 04^{\prime} 49.51^{\prime \prime} \mathrm{N}$ & $1538 \mathrm{~m}$ & 3900 & 204 \\
Lidar supersite & $105^{\circ} 00^{\prime} 14.36^{\prime \prime} \mathrm{W}$ & $40^{\circ} 02^{\prime} 55.72^{\prime \prime} \mathrm{N}$ & $1580 \mathrm{~m}$ & - & - \\
\hline
\end{tabular}

tions of the three scanning Doppler wind lidars are shown in Fig. 1, while their GPS positions, azimuthal angles and distance with respect to the virtual-tower location are reported in Table 1. Accuracy in the radial velocity of each scanning lidar is always better than $0.3 \mathrm{~m} \mathrm{~s}^{-1}$ for carrierto-noise ratio higher than $-25 \mathrm{~dB}$ for the line-of-sight velocity (Choukulkar et al., 2017). Squareness, precision and repeatability tests indicate an absolute pointing accuracy of about $0.15^{\circ}$. All the scanning lidars performed fixed-point measurements at different heights over the lidar supersite location (Fig. 1) during the time period 00:00-24:00 UTC on 25 March 2015. Lidar measurements were performed at six different heights from 100 to $200 \mathrm{~m}$ with $20 \mathrm{~m}$ steps.

For the measurements performed on 25 March 2015, the maximum and minimum range for scanning Doppler lidars varied from 300 up to $3000 \mathrm{~m}$, while the carrier-to-noise ratio was between -50 and $3 \mathrm{~dB}$. The collected lidar data were further post-processed only when the carrier-to-noise ratio of the lidar signal was larger than $-25 \mathrm{~dB}$ (Carbajo-Fuertes et al., 2014). The post-processing from the three radial velocities $\left(U_{\mathrm{r}}\right)$ to Cartesian wind velocity components $(U, V$, $W$ ) was carried out following the standard triple-Doppler retrieval (Mikkelsen et al., 2008; Mann et al., 2009; CarbajoFuertes et al., 2014; Debnath et al., 2017; Choukulkar et al., 2017; Simley et al., 2016) by means of the following equations:

$$
\begin{aligned}
{\left[\begin{array}{l}
U \\
V \\
W
\end{array}\right]=} & {\left[\begin{array}{ccc}
\cos \left(\phi_{\mathrm{UTD}}\right) * \cos \left(\theta_{\mathrm{UTD}}\right) & \cos \left(\phi_{\mathrm{UTD}}\right) * \sin \left(\theta_{\mathrm{UTD}}\right) & \sin \left(\phi_{\mathrm{UTD}}\right) \\
\cos \left(\phi_{D 1}\right) * \cos \left(\theta_{D 1}\right) & \cos \left(\phi_{D 1}\right) * \sin \left(\theta_{D 1}\right) & \sin \left(\phi_{D 1}\right) \\
\cos \left(\phi_{D 2}\right) * \cos \left(\theta_{D 2}\right) & \cos \left(\phi_{D 2}\right) * \sin \left(\theta_{D 2}\right) & \sin \left(\phi_{D 2}\right)
\end{array}\right]^{-1} } \\
& \times\left[\begin{array}{c}
U_{\mathrm{r}}^{\mathrm{UTD}} \\
U_{\mathrm{r}}^{D 1} \\
U_{\mathrm{r}}^{D 2}
\end{array}\right]
\end{aligned}
$$

where $\phi$ and $\theta$ represent elevation and azimuthal angles, respectively, of the various lidars indicated as a suffix. The accuracy in the retrieval of the three velocity components was estimated for the different heights through the $L_{2}$ norm of the rows of the matrix in Eq. (1), including trigonometric functions of $\phi$ and $\theta$ of the various lidars. Error in the velocity retrieval increases as the $L_{2}$ norm of the rows of the matrix in Eq. (1) diverges from 1; however, the values obtained with this criterion do not represent any error quantification and can only be used for a comparative analysis and selection of optimal lidar configurations (Simley et al., 2016). In Table 2,
Table 2. Error analysis on the retrieval of the wind velocity components from triple-Doppler lidar measurements for different heights consequent to azimuthal and elevation angles of the three lidars. Values are dimensionless.

\begin{tabular}{lrrr}
\hline Height $(\mathrm{m})$ & $U$ & $V$ & $W$ \\
\hline 100 & 0.9984 & 1.3421 & 2.6096 \\
120 & 1.0015 & 1.3541 & 2.2071 \\
140 & 1.0052 & 1.3682 & 1.9242 \\
160 & 1.0094 & 1.3843 & 1.7157 \\
180 & 1.0142 & 1.4023 & 1.5567 \\
200 & 1.0195 & 1.4222 & 1.4323 \\
\hline
\end{tabular}

it is shown that for this setup the accuracy in the retrieval of the horizontal wind speed components is roughly unchanged for the different heights, while accuracy is improved with increasing heights for the vertical velocity, which is consequence of the higher elevation angles of the three lidars.

For each height of the virtual tower and each lidar, the closest range gate to the considered measurement point is selected for the data retrieval. The maximum horizontal distance of a gate centroid from the respective tower measurement point is $19 \mathrm{~m}$, while the vertical one is always smaller than $10 \mathrm{~m}$. The sampling period at each measurement point was $25 \mathrm{~s}$, while the total time required to perform one virtual tower was on average $151.6 \mathrm{~s}$. The lidars used for the XPIA field campaign are commercial lidars operated with a graphical user interface (GUI) provided by the lidar manufacturer. This GUI did not allow the control and synchronization of the lidars through a master computer; thus, at each measurement location the overlapping time was generally smaller than the prefixed period of $25 \mathrm{~s}$. A histogram of the overlapping time is reported in Fig. 2, which shows a mean value of $16.3 \mathrm{~s}$ and a standard deviation of $3.6 \mathrm{~s}$.

Bias errors in laser pointing and in the line-of-sight velocity, which were evaluated through preliminary tests (Lundquist et al., 2016) and reported in Table 3, were considered for the data retrieval. An estimate of the azimuthal bias from the north for each lidar was retrieved through hardtarget tests performed by hitting reference towers present on site with the lidar laser beam, and using their GPS coordi- 


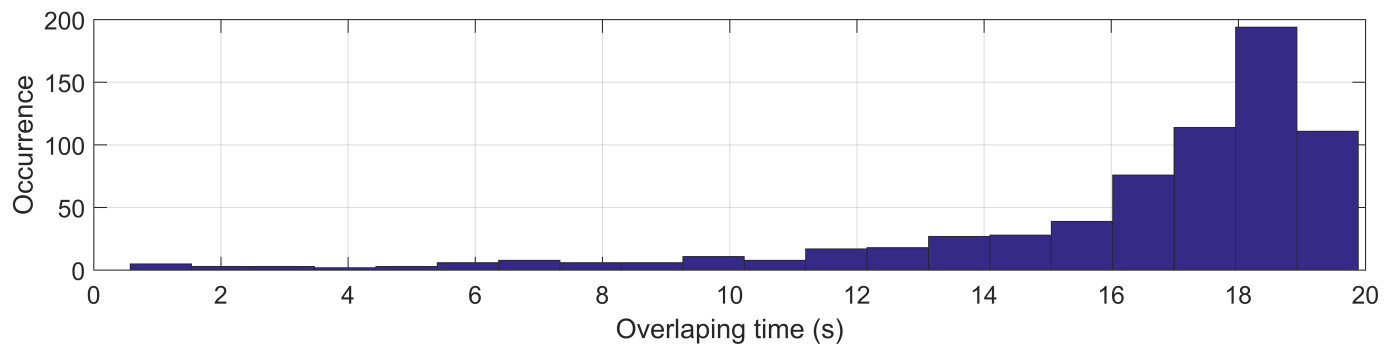

Figure 2. Histogram of the overlapping time of the step-stare measurements among the three lidars.

Table 3. Bias errors used for the triple-Doppler data retrieval.

\begin{tabular}{lrrrr}
\hline & $\begin{array}{r}\text { Scanner } \\
\text { height } \\
(\mathrm{m})\end{array}$ & $\begin{array}{r}\text { Azimuth } \\
\left({ }^{\circ}\right)\end{array}$ & $\begin{array}{r}\text { Elevation } \\
\left({ }^{\circ}\right)\end{array}$ & $\begin{array}{r}\text { los } \\
\text { velocity } \\
\left(\mathrm{m} \mathrm{s}^{-1}\right)\end{array}$ \\
\hline UTD & 1.37 & 4.93 & -0.89 & 0.6 \\
Dalek 1 & 1.37 & 3.45 & 0.0 & 0.0 \\
Dalek 2 & 1.37 & 7.70 & 0.0 & 0.0 \\
\hline
\end{tabular}

nates with respect to the lidar location. A bias in the radial velocity of the UTD lidar was due to improper calibration of the frequency chirp in the laser pulse, which was stable and reproducible in several tests, and could simply be subtracted out of the lidar measurements.

We note that the sonic anemometers can experience wake effects from the tower for specific wind directions, i.e., $111^{\circ} \leq \theta \leq 197^{\circ}$ for the NW anemometers and $299^{\circ} \leq$ $\theta \leq 20^{\circ}$ for the SE anemometers (Lundquist et al., 2016; McCaffrey et al., 2017). For this experiment, wind direction varied between 360 and $0^{\circ}$, which indicates that the SE and NW anemometers might be affected by wake effects for certain period of time.

\section{Assessment of radar virtual-tower measurements}

Assessment of the lidar and radar virtual towers is performed against the wind velocity components acquired through the sonic anemometers deployed throughout the height of the BAO met-tower and vertical profiles of the 3-D wind velocity sampled with a lidar profiler deployed at the lidar supersite location. These data acquired are shown in Fig. 3 for the height of $150 \mathrm{~m}$. In this figure, ranges of the wind direction for which the sonic anemometers may experience tower wake effects are reported with shaded areas (Lundquist et al., 2016; McCaffrey et al., 2017). For few time stamps, some differences are observed for the wind data obtained from the two sonic anemometers, which might be a consequence of the statistical steadiness of the acquired wind signals and the duration of the measurement sampling period. A generally good agreement is observed among the different instruments
Table 4. Linear regression analysis among the V2 lidar, SE sonic anemometer and NW sonic anemometer data for $24 \mathrm{~h}$ data reported in Fig. 3.

\begin{tabular}{|c|c|c|}
\hline $\begin{array}{l}\text { Height } \\
\text { (m) }\end{array}$ & $\begin{array}{c}U_{\mathrm{h}} R^{2} \\
\text { (slope) }\end{array}$ & $\begin{array}{r}\text { Wind dir. } R^{2} \\
\text { (slope) }\end{array}$ \\
\hline \multicolumn{3}{|c|}{ SE sonic vs. NW sonic } \\
\hline 100 & $0.97(1.00)$ & $0.97(1.06)$ \\
\hline 150 & $0.97(1.00)$ & $0.97(1.07)$ \\
\hline 200 & $0.98(1.00)$ & $0.96(1.08)$ \\
\hline All heights together & $0.97(1.00)$ & $0.97(1.07)$ \\
\hline \multicolumn{3}{|c|}{ V2 lidar vs. NW sonic } \\
\hline 100 & $0.92(0.94)$ & $0.88(0.96)$ \\
\hline 150 & $0.91(0.93)$ & $0.92(1.00)$ \\
\hline 200 & $0.86(0.80)$ & $0.94(0.96)$ \\
\hline All heights together & $0.90(0.90)$ & $0.91(0.97)$ \\
\hline \multicolumn{3}{|c|}{ V2 lidar vs. SE sonic } \\
\hline 100 & $0.92(0.93)$ & $0.89(0.90)$ \\
\hline 150 & $0.90(0.93)$ & $0.93(0.96)$ \\
\hline 200 & $0.76(0.77)$ & $0.96(0.97)$ \\
\hline All heights together & $0.90(0.91)$ & $0.91(0.92)$ \\
\hline
\end{tabular}

for both horizontal wind speed, $U_{\mathrm{h}}$, and wind direction for the entire duration of the experiment.

In order to perform comparison and linear regression analysis between wind data acquired from different instruments, data acquired from instruments with a higher sampling frequency are averaged over the corresponding sampling period of instruments with a lower sampling frequency. For instance, sonic anemometer data acquired with a sampling frequency of $20 \mathrm{~Hz}$ are averaged over periods with a duration of $1 \mathrm{~s}$ for comparison with V2 lidar data acquired with a sampling frequency of $1 \mathrm{~Hz}$.

Linear regression analysis performed between sonic anemometer and the V2 lidar data generally shows a good correlation among the different instruments for the different heights. In Table 4 , the slope and $R^{2}$ values resulting from the linear regression analysis are reported for the different heights and as overall ensemble statistics. It is noteworthy that Tables 4 and 5 include sonic anemometer data acquired 

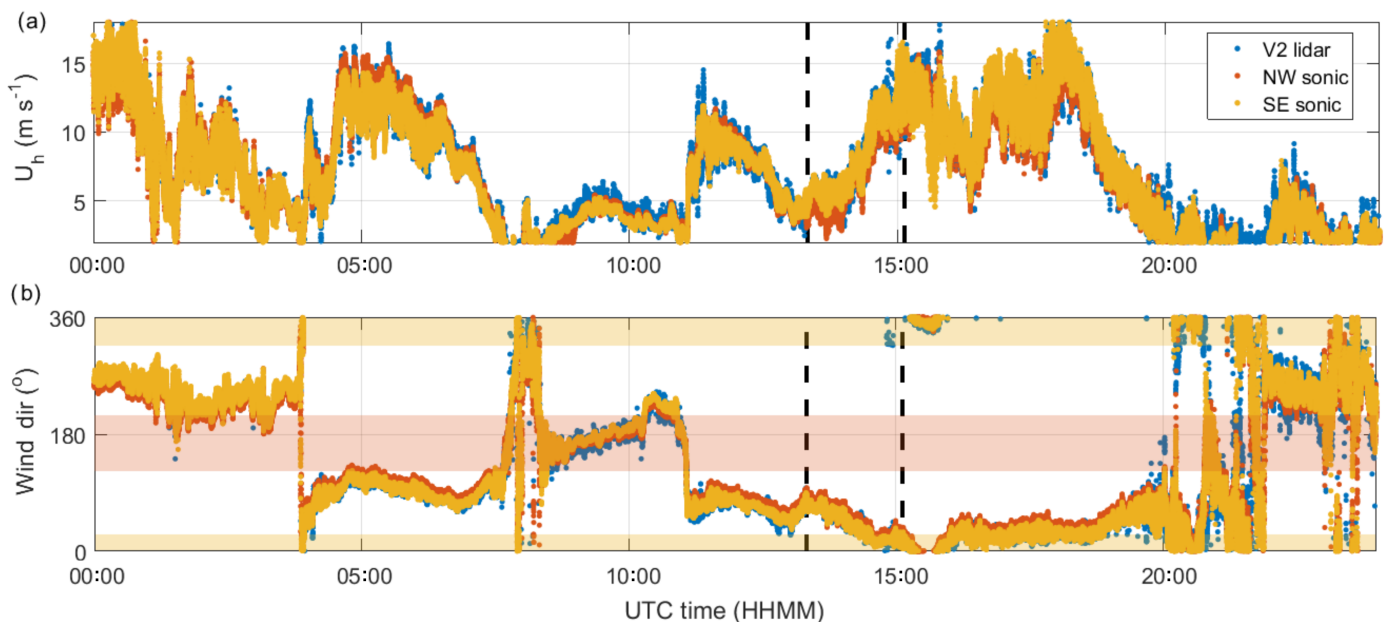

Figure 3. Wind velocity data acquired from sonic anemometers and lidar profiler at $150 \mathrm{~m}$ height: (a) horizontal wind speed $U_{\mathrm{h}}\left(\mathrm{m} \mathrm{s}^{-1}\right)$; (b) wind direction $\left(^{\circ}\right)$. The date of the observation is 25 March 2015. Two vertical dashed lines represent the availability period of radar data.

Table 5. Linear regression analysis of Ka-band radars against sonic anemometer and V2 lidar data.

\begin{tabular}{lrr}
\hline $\begin{array}{l}\text { Height } \\
(\mathrm{m})\end{array}$ & $\begin{array}{r}U_{\mathrm{h}} R^{2} \\
(\text { slope })\end{array}$ & $\begin{array}{r}\text { Wind dir. } R^{2} \\
\text { (slope })\end{array}$ \\
\hline \multicolumn{3}{c}{ Dual-Doppler radar vs. V2 lidar } \\
\hline 100 & $0.89(1.02)$ & $0.90(0.90)$ \\
120 & $0.93(1.04)$ & $0.92(0.90)$ \\
140 & $0.93(1.06)$ & $0.91(0.86)$ \\
150 & $0.92(1.06)$ & $0.92(0.89)$ \\
160 & $0.93(1.08)$ & $0.92(0.86)$ \\
180 & $0.93(1.12)$ & $0.91(0.84)$ \\
200 & $0.93(1.12)$ & $0.90(0.82)$ \\
All heights together & $0.92(1.08)$ & $0.91(0.87)$ \\
\hline \multicolumn{3}{c}{ Dual-Doppler radar vs. NW sonic } \\
\hline 100 & $-(-)$ & $-(-)$ \\
150 & $0.91(1.03)$ & $0.93(0.83)$ \\
200 & $0.95(0.92)$ & $0.96(0.87)$ \\
All heights together & $0.93(0.97)$ & $0.94(0.84)$ \\
\hline \multicolumn{3}{c}{ Dual-Doppler radar vs. SE sonic } \\
\hline 100 & $0.87(1.10)$ & $0.95(0.89)$ \\
150 & $0.93(1.07)$ & $0.93(0.86)$ \\
200 & $-(-)$ & $-(-)$ \\
All heights together & $0.91(1.10)$ & $0.95(0.87)$ \\
\hline
\end{tabular}

under wake distortion produced by the met-tower (McCaffrey et al., 2017). Given the good agreement between the sonic anemometers and the profiling lidars, we felt confident that the data sets from these two types of instruments can be used to evaluate the accuracy of virtual-tower measurements with scanning radars and lidars.

In this section, we present the assessment of the dualDoppler measurements performed with the two Ka-band radars against sonic anemometer and lidar profiler wind velocity data. For the retrieval of the horizontal wind speed and wind direction through the dual-Doppler technique, the vertical velocity is assumed to be negligible, which allows dropping the last row in Eq. (1). In Fig. 4, horizontal wind speed and wind direction at $150 \mathrm{~m}$ height retrieved from the abovementioned instruments are compared. The considered wind data were acquired by the various instruments at the same height of $150 \mathrm{~m}$; thus no data interpolation was needed for this analysis. A generally good qualitative agreement can already be perceived.

In order to achieve a more quantitative characterization of the accuracy in the dual-Doppler retrieval performed on the radar data, a linear regression analysis was then performed for both horizontal wind speed and wind direction. In order to compare radar data with sonic and V2 lidar data over different heights, a 1-D linear interpolation was performed for each time stamp in order to estimate the radar wind value for the heights probed by the sonic anemometers and the V2 lidar. The correlation between the radar data and the other reference instruments is generally very high, as shown in Fig. 5, with a correlation always larger than $91 \%$. Slope and $R^{2}$ values resulting from the linear regression analysis among dualDoppler radar data, sonic anemometer and V2 lidar data are then reported in Table 5 for the various heights and as ensemble statistics. Again, a good agreement between radar and reference instrument data is generally achieved throughout the height of the virtual tower and without any noticeable trend in the vertical direction.

Finally, histograms of the difference between the horizontal wind speed and wind direction measured through the dual-Doppler radar measurements and the reference instruments are reported in Fig. 6. For the horizontal wind speed the mean difference is $-0.47,-0.11$ and $-0.63 \mathrm{~m} \mathrm{~s}^{-1}$ compared with the V2 lidar, NW sonic and SE sonic, respectively, 


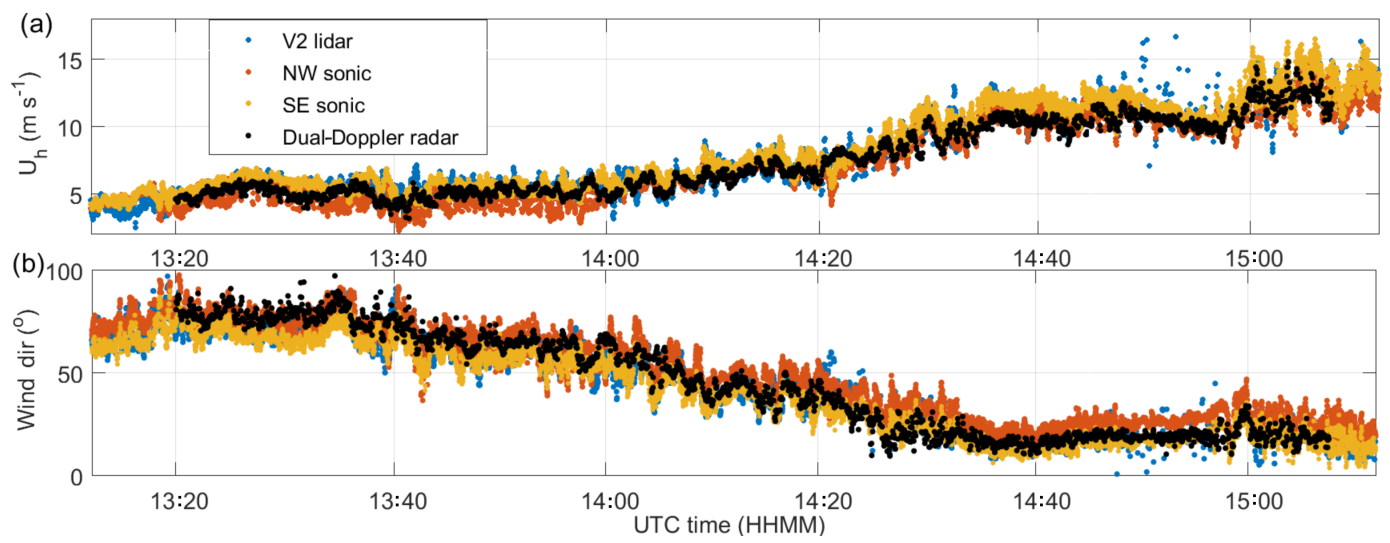

Figure 4. Dual-Doppler radar measurements at $150 \mathrm{~m}$ height compared with sonic anemometer and V2 lidar data: (a) horizontal wind speed $U_{\mathrm{h}}\left(\mathrm{m} \mathrm{s}^{-1}\right)$; (b) wind direction $\left(^{\circ}\right)$. The date of the observation is 25 March 2015.
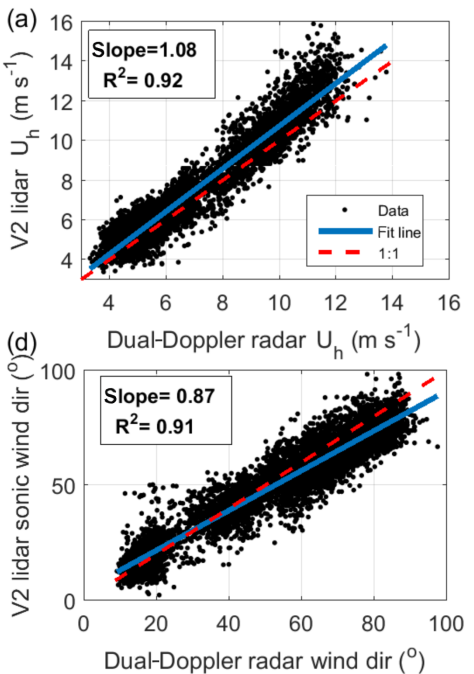
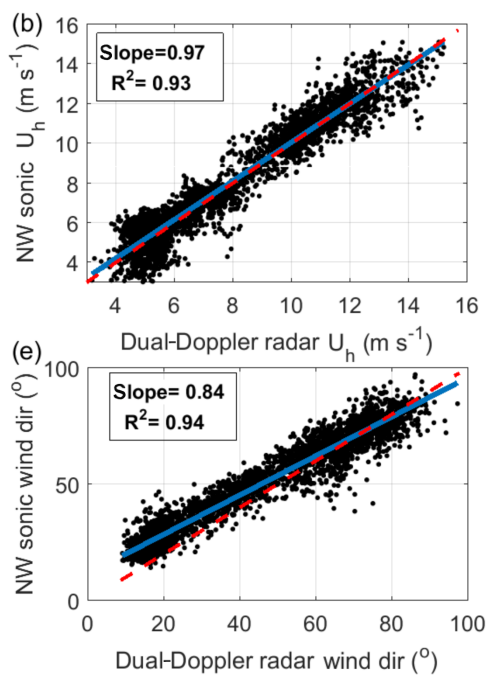
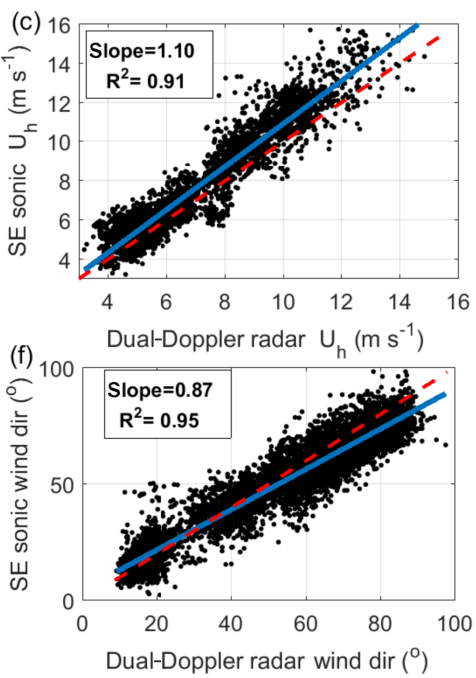

Figure 5. Linear regression analysis of the dual-Doppler radar retrieval against sonic anemometer and V2 lidar data for all the tested heights: (a-c) horizontal wind speed $U_{\mathrm{h}}\left(\mathrm{m} \mathrm{s}^{-1}\right)$; (d-f) wind direction $\left(^{\circ}\right)$.

with standard deviations of $0.68,0.78$ and $0.86 \mathrm{~m} \mathrm{~s}^{-1}$. A similar analysis for the wind direction leads to a mean difference of $2.6,-4.75$ and $2.60^{\circ}$ compared with the V2 lidar, NW sonic and SE sonic, respectively, with standard deviations of $6.98,6.28,6.98^{\circ}$.

\section{Retrieval and assessment of triple-Doppler lidar measurements}

In this section, we present an assessment study of the tripleDoppler lidar measurements which were performed with three scanning Doppler lidars to retrieve the three velocity components. As for the previous section, assessment of triple-Doppler data is carried out against sonic anemometer and lidar profiler data. In Fig. 7a, the line-of-sight velocities are reported for the measurements carried out at $100 \mathrm{~m}$ height during the entire period of the experiments. The wind data considered for the triple-Doppler retrieval are first qualitycontrolled as a function of the carrier-to-noise ratio (minimum value of $-25 \mathrm{~dB}$ ) and then averaged over the actual sampling period, which is defined as the time for which the three lidars measured simultaneously over the location of interest. Statistics of the actual sampling period, i.e., of the overlapping time among the three scanning lidars, have been already presented in Fig. 2.

The retrieved vertical velocity was assessed only against the V2 lidar data, because the horizontal distance of $134 \mathrm{~m}$ between the BAO tower and the lidar supersite location (see Table 1) as well as the different averaging volume of each instrument leads to poorer agreement between sonic anemometer and triple-Doppler lidar data, as reported in Table 6. The linear regression in the vertical velocity with the V2 lidar data, in contrast, shows a good agreement for the height of $200 \mathrm{~m}$ with a slope of 0.94 and a correlation of $R^{2}=0.79$. 

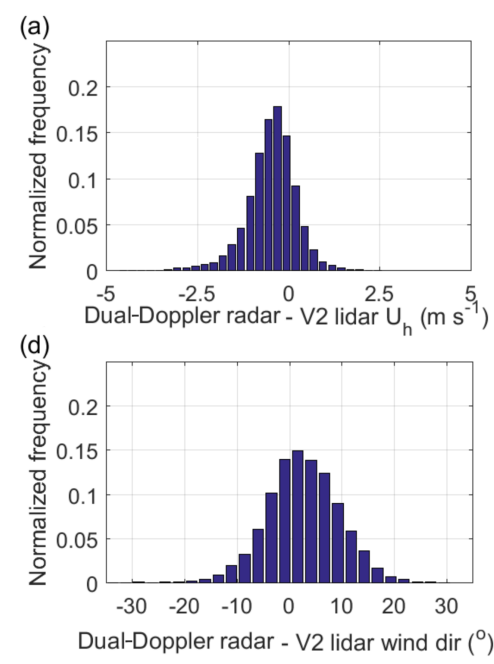

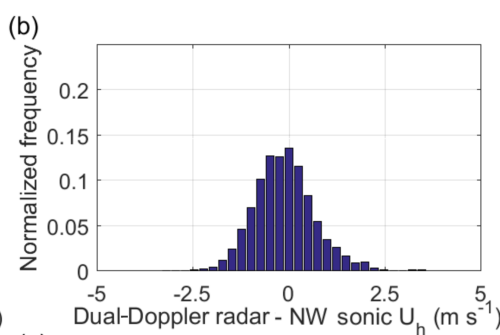
(e)

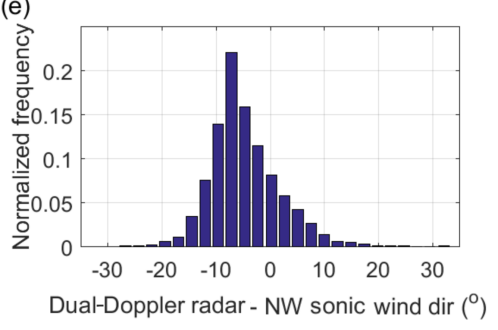

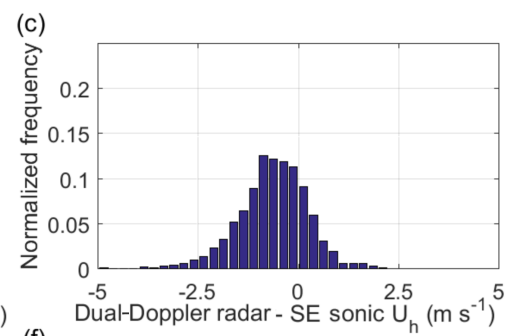

(f)

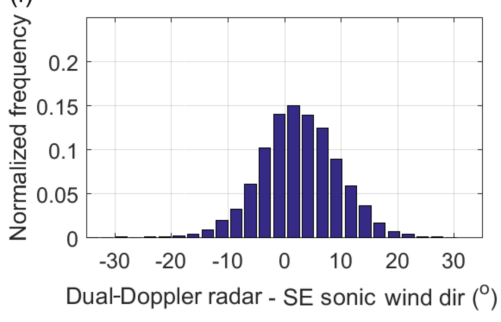

Figure 6. Difference of dual-Doppler radar retrieval with the reference instruments, i.e., sonic anemometers and V2 lidar, for all the tested heights: (a-c) horizontal wind speed $U_{\mathrm{h}}\left(\mathrm{m} \mathrm{s}^{-1}\right)$; (d-f) wind direction $\left(^{\circ}\right)$.
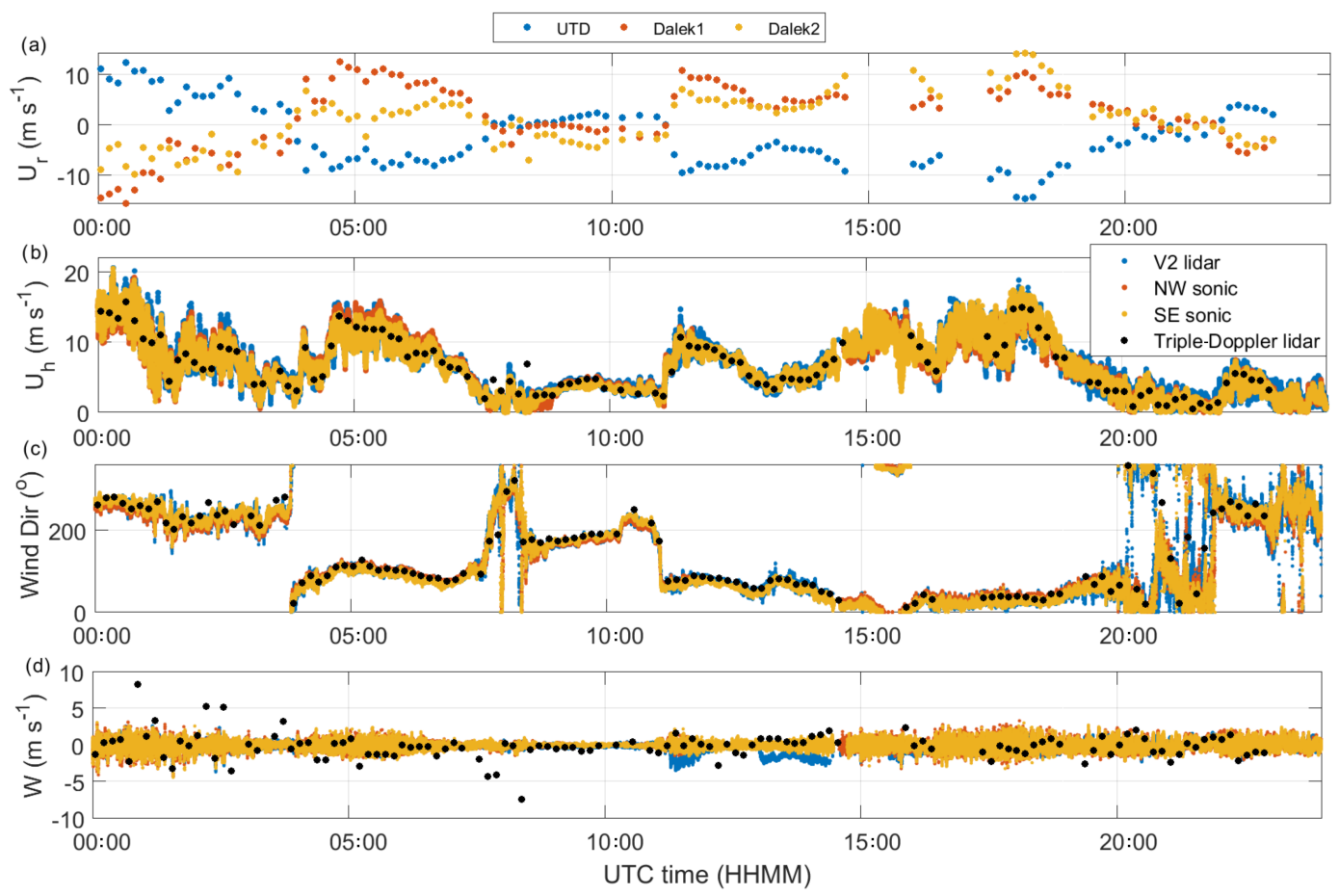

Figure 7. Triple-Doppler lidar measurements at $100 \mathrm{~m}$ height and assessment against sonic anemometer and lidar profiler data: (a) lineof-sight velocities from the three scanning lidars; (b) horizontal wind speed $U_{\mathrm{h}}\left(\mathrm{m} \mathrm{s}^{-1}\right)$; (c) wind direction $\left(^{\circ}\right)$; $(\mathbf{d})$ vertical velocity $W$ $\left(\mathrm{m} \mathrm{s}^{-1}\right)$.

As predicted from the error analysis presented in Table 2, the reduced elevation angles of the lidar laser beams for smaller heights lead to a rapid decay in the accuracy for the retrieval of the vertical velocity through the triple-Doppler lidar measurements.

The horizontal wind speed and direction retrieved through the triple-Doppler lidar measurements are reported in Fig. 7b and $c$, respectively. In these figures, the respective velocity data directly measured at $100 \mathrm{~m}$ height highlight that - just as for more traditional instruments, such as sonic anemometers and the lidar profiler - the triple-Doppler measurement technique allows characterization of a significant daily variability in wind velocity from quiescent conditions up to about $20 \mathrm{~m} \mathrm{~s}^{-1}$. Good performance is also observed for the charac- 

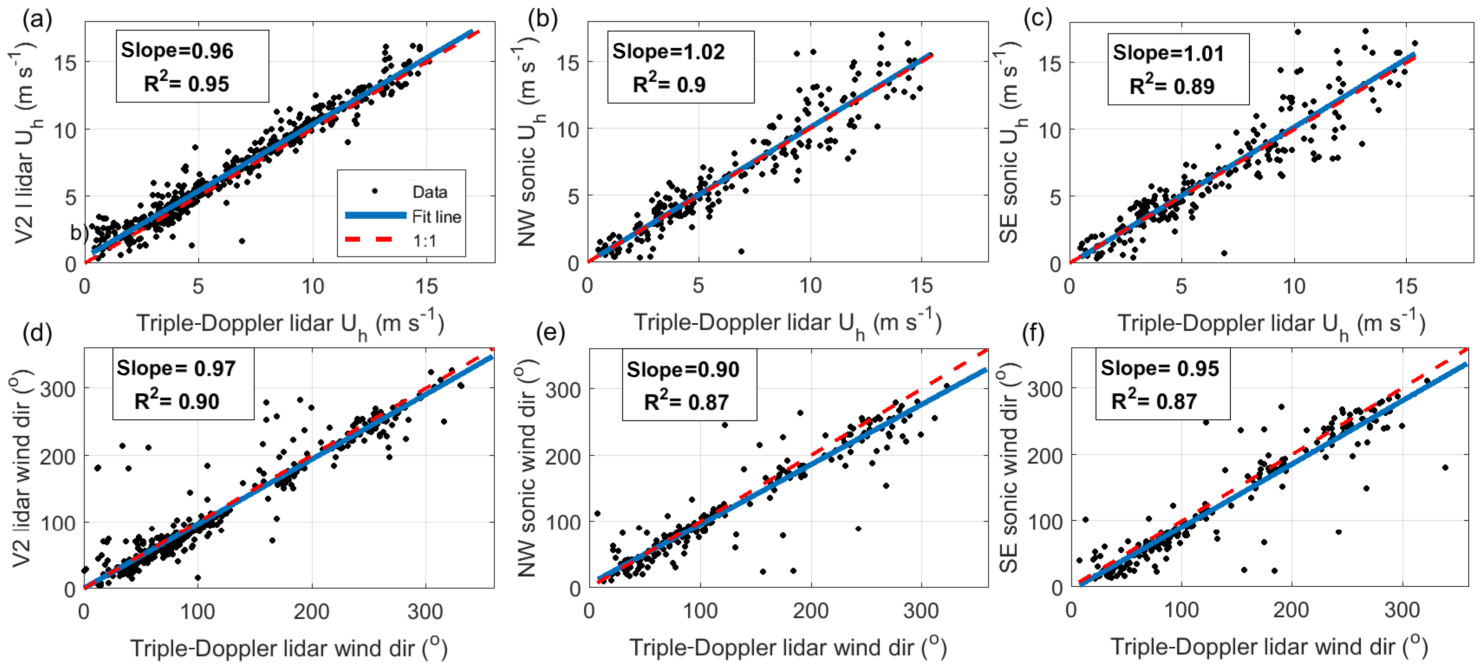

Figure 8. Linear regression of triple-Doppler lidar data against reference instruments for all the tested heights: (a-c) horizontal wind speed $U_{\mathrm{h}}\left(\mathrm{m} \mathrm{s}^{-1}\right) ;(\mathbf{d}-\mathbf{f})$ wind direction $\left(^{\circ}\right)$.

Table 6. Linear regression analysis of triple-Doppler lidar data against the reference instruments, namely sonic anemometers and V2 lidar.

\begin{tabular}{|c|c|c|c|}
\hline $\begin{array}{l}\text { Height } \\
\text { (m) }\end{array}$ & $\begin{array}{l}U_{\mathrm{h}} R^{2} \\
\text { (slope) }\end{array}$ & $\begin{array}{r}\text { Wind dir. } R^{2} \\
\text { (slope) }\end{array}$ & $\begin{array}{l}W R^{2} \\
\text { (slope) }\end{array}$ \\
\hline \multicolumn{4}{|c|}{ Triple-Doppler lidar vs. V2 lidar } \\
\hline 100 & $0.94(0.99)$ & $0.92(0.97)$ & $0.01(0.13)$ \\
\hline 120 & $0.97(0.99)$ & $0.93(0.95)$ & $0.27(0.32)$ \\
\hline 140 & $0.97(0.97)$ & $0.85(0.97)$ & $0.57(0.52)$ \\
\hline 160 & $0.94(0.97)$ & $0.88(0.93)$ & $0.62(0.63)$ \\
\hline 180 & $0.95(1.00)$ & $0.95(0.92)$ & $0.77(0.68)$ \\
\hline 200 & $0.93(1.07)$ & $0.99(1.00)$ & $0.79(0.94)$ \\
\hline All heights together & $0.96(0.95)$ & $0.90(0.97)$ & $0.49(0.42)$ \\
\hline \multicolumn{4}{|c|}{ Triple-Doppler lidar vs. NW sonic } \\
\hline 100 & $0.92(0.89)$ & $0.85(0.90)$ & $0.008(0.04)$ \\
\hline 200 & $0.90(1.12)$ & $0.90(0.91)$ & $0.13(0.12)$ \\
\hline All heights together & $0.90(1.02)$ & $0.87(0.90)$ & $0.09(0.1)$ \\
\hline \multicolumn{4}{|c|}{ Triple-Doppler lidar vs. SE sonic } \\
\hline 100 & $0.89(1.12)$ & $0.84(0.91)$ & $0.005(0.012)$ \\
\hline 200 & $0.9(0.94)$ & $0.93(1.00)$ & $0.092(0.11))$ \\
\hline All heights together & $0.89(1.01)$ & $0.87(0.95)$ & $0.03(0.08)$ \\
\hline
\end{tabular}

terization of the wind direction. Indeed, during the experiment, wind direction varied all around the full angle of the wind rose, and the triple-Doppler measurements were able to detect the different angles of the wind direction and follow its variability as a function of time.

Accuracy in the triple-Doppler retrieval of horizontal wind speed and direction is then quantitatively characterized through a linear regression analysis, which was performed for all the heights under examination against sonic anemometer and lidar profiler data (Fig. 8). Starting with a comparison with the V2 lidar profiler data located over the lidar supersite location, a very good agreement is estimated between these measurement techniques. For the horizontal wind speed, the slope is 0.96 with a correlation of $R^{2}=0.95$, while for the wind direction the slope is 0.97 and there is a correlation of $R^{2}=0.9$.

Moving to the linear regression of the triple-Doppler lidar against sonic anemometer data (Fig. 8), the horizontal distance of $134 \mathrm{~m}$ between the BAO tower and the lidar supersite location, where all the scanning lidars are focused, does not significantly affect the agreement between measurements obtained from the various instruments. Indeed, the slope for the wind velocity varies between 0.9 and 1.02 , with correlation always larger than $R^{2}=0.89$. For the wind direction, the slope is 0.9 and 0.95 for the linear regression against NW and SE sonic anemometers, respectively, while the correlation is $R^{2}=0.87$.

Results of the linear regression analysis for the measurements carried out at different heights are reported in Table 6. Considering the data against the V2 lidar, the slope for the horizontal wind speed is always very close to 1 , with a minimum value of 0.97 and a maximum value of 1.07 , while the correlation is always larger than $R^{2}=0.93$. For the wind direction, a reduced level of accuracy is estimated with a correlation larger than $R^{2}=0.88$ but with the slope still very close to 1 . As for the error analysis due to to the setup of the three lidars (see Table 2), accuracy in the measurements for both horizontal wind speed and wind direction is not noticeably changed for the locations at different heights.

Finally, histograms of the difference between the horizontal wind speed and direction measured through the tripleDoppler lidar measurements and the reference instruments are reported in Fig. 9. For the horizontal wind speed, the mean differences are $-0.38,-0.06$ and $-0.09 \mathrm{~m} \mathrm{~s}^{-1} \mathrm{~s}$, and 
(a)

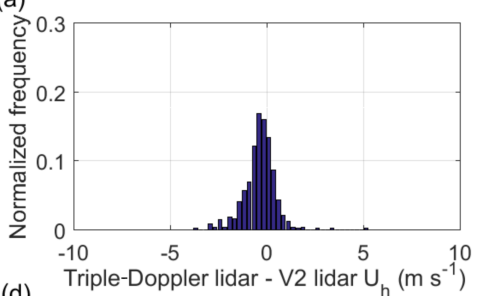

(d)

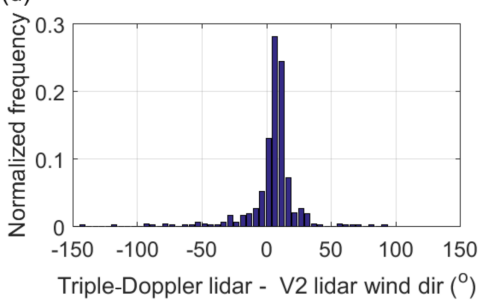

(b)

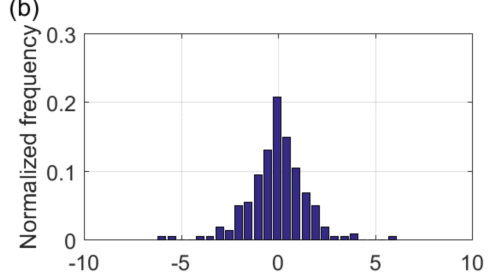

(e)

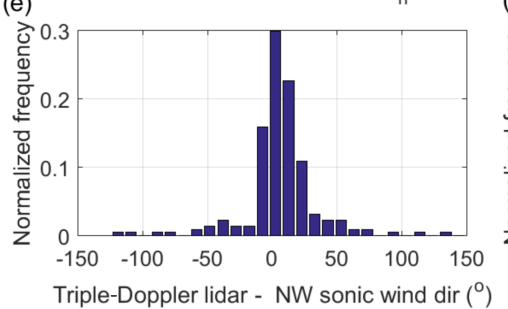

(c)

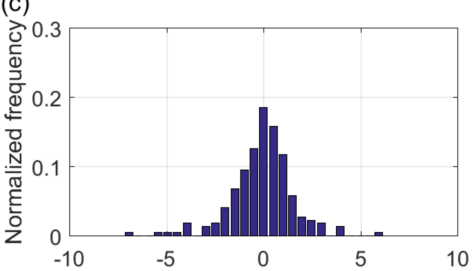

f) Triple-Doppler lidar - SE sonic $U_{h}\left(\mathrm{~m} \mathrm{~s}^{-1}\right)$

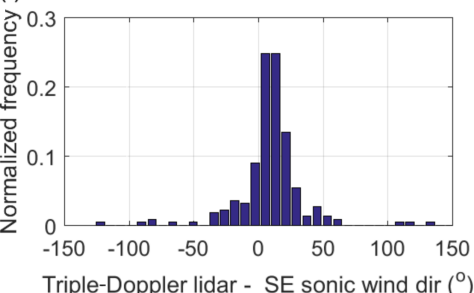

Figure 9. Difference of triple-Doppler lidar retrieval with reference instruments for all the tested heights: (a-c) horizontal wind speed $U_{\mathrm{h}}$ $\left(\mathrm{m} \mathrm{s}^{-1}\right) ;(\mathbf{d}-\mathbf{f})$ wind direction $\left(^{\circ}\right)$.

the standard deviations are $0.83,1.43$ and $1.60 \mathrm{~m} \mathrm{~s}^{-1}$ with respect to the V2 lidar, NW sonic and SE sonic, respectively. A similar analysis for the wind direction leads to a mean difference of 3.36, 7.47 and $11.14^{\circ}$ with standard deviations of $25.68,26.09$ and $27.15^{\circ}$ compared with the V2 lidar, NW sonic and SE sonic, respectively.

\section{Comparison between lidar and radar virtual-tower measurements}

After discussing the assessment of the virtual-tower measurements against the reference instruments, namely sonic anemometers installed over the BAO met-tower and a lidar profiler, a direct intercomparison between Ka-band radar and wind lidar data is now presented.

According to the linear regression analysis presented in Sects. 3 and 4, a very good level of agreement for both radar and triple-Doppler lidar data was observed with reference instruments, as detailed in Tables 5 and 6. Generally, the slope obtained for the correlation analysis was very close to 1 for both measurement techniques in the estimate of wind velocity (between 0.97 and 1.08 for radar data and between 0.95 and 1.02 for lidar data) and wind direction (between 0.84 and 0.87 for radar data and between 0.9 and 0.97 for lidar data). Correlation between the virtual-tower measurements and data obtained from sonic anemometers and the V2 lidar is always larger than $R^{2}>0.91$ for the radar measurements and $R^{2}>0.87$ for the triple-Doppler lidar data. No systematic bias errors have been observed for both radar and tripleDoppler lidar measurements for the retrieval of the horizontal wind speed and wind direction (see Figs. 6 and 9).

In Fig. 10, a qualitative comparison between the wind data retrieved through the dual-Doppler radar measurements and the triple-Doppler lidar data is presented. Radar virtual-tower measurements were performed continuously over the lidar supersite location with an average sampling period for each virtual tower of $3.3 \mathrm{~s}$. Triple-Doppler lidar measurements, in contrast, were performed every 10 min due to a test schedule including other scans than these presented in this paper. Generally good agreement is observed when virtual towers have been performed simultaneously with the two Ka-band radars and the three scanning wind lidars. A similar variability in time and over the different heights was observed through the two different measurement techniques. Differences between the radar and the lidar measurements, for both horizontal wind speed and wind direction, were generally very small compared to the variability observed as functions of time and height.

In Fig. 11, statistics of the difference between the radar and lidar measurements are reported for the different virtual towers performed. For the wind velocity, the difference averaged over the height is always smaller than $0.5 \mathrm{~m} \mathrm{~s}^{-1}$ with a maximum standard deviation of $0.29 \mathrm{~m} \mathrm{~s}^{-1}$. For the wind direction, the maximum difference averaged over height is always smaller than $10^{\circ}$, and the maximum standard deviation is $4.79^{\circ}$.

\section{Concluding remarks}

During the XPIA experiment, colocated virtual-tower measurements were performed with two Ka-band radars and three scanning Doppler wind lidars. Therefore, these tests provided the unique opportunity to perform a direct intercomparison between dual-Doppler radar and triple-Doppler lidar measurements. Furthermore, wind data obtained from the virtual-tower measurements were also assessed against sonic anemometer data acquired from a met-tower located at a distance of $134 \mathrm{~m}$ from the virtual-tower location and a li- 

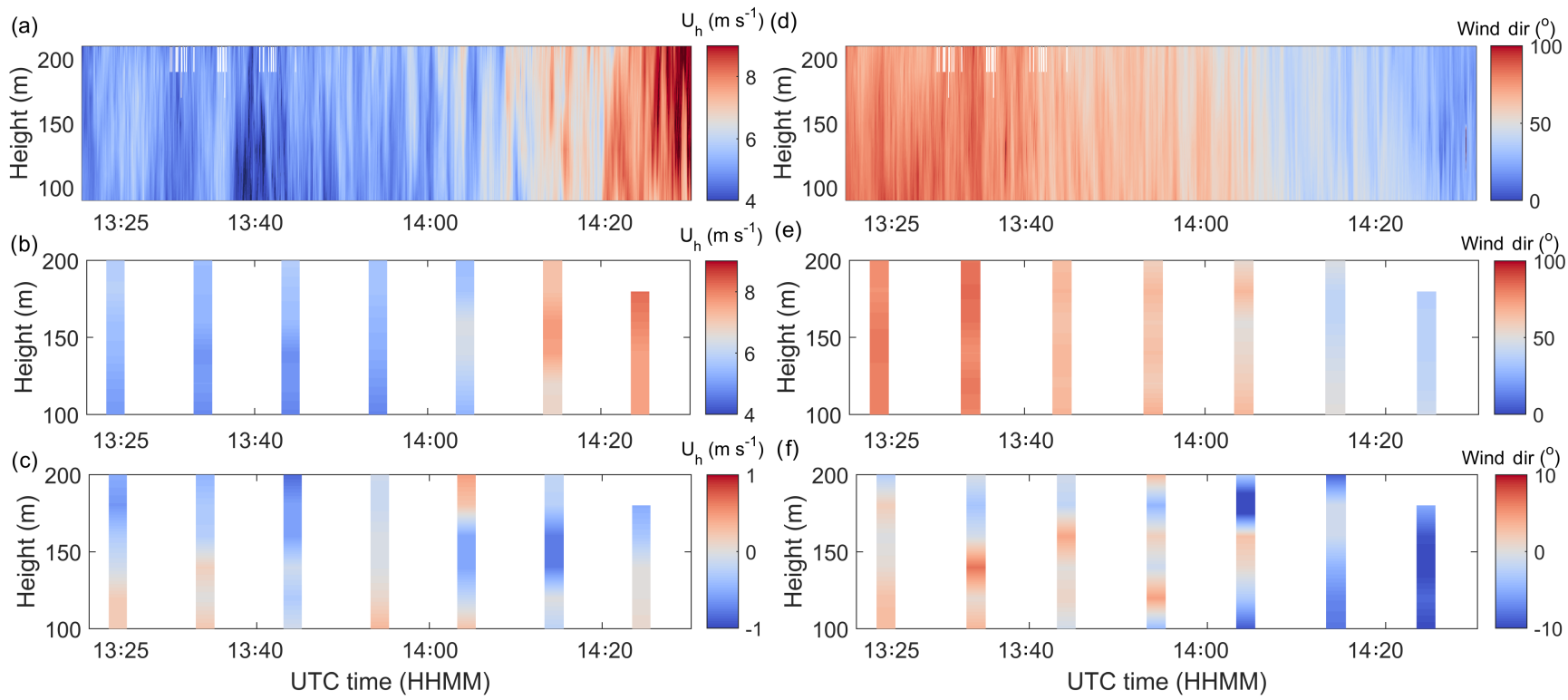

Figure 10. Intercomparison between radar and lidar virtual-tower measurements: (a) horizontal wind speed $U_{\mathrm{h}}\left(\mathrm{m} \mathrm{s}^{-1}\right)$ retrieved with dualDoppler radar; (b) horizontal wind speed $U_{\mathrm{h}}\left(\mathrm{m} \mathrm{s}^{-1}\right)$ retrieved with triple-Doppler lidar; (c) difference in horizontal wind speed $U_{\mathrm{h}}\left(\mathrm{m} \mathrm{s}^{-1}\right)$ between lidar and radar data; (d) wind direction retrieved from dual-Doppler radar; (e) wind direction retrieved from triple-Doppler lidar; (f) difference in wind direction between lidar and radar data.

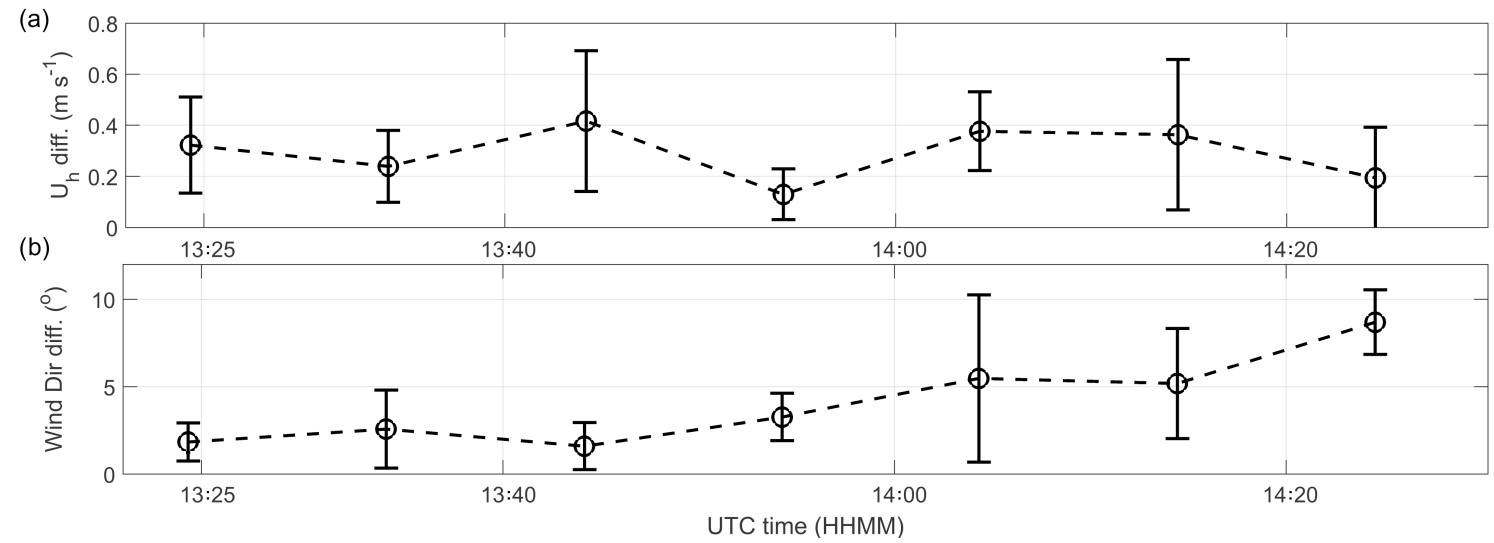

Figure 11. Statistics of the absolute value of the difference between radar and lidar wind data averaged over all the available heights: (a) horizontal wind speed $U_{\mathrm{h}}\left(\mathrm{m} \mathrm{s}^{-1}\right)$ difference; (b) wind direction difference. Circles represent mean value, while error bars represent standard deviation.

dar profiler that, in contrast, was colocated with the virtual towers.

Results of this assessment study show that - besides the use of different technologies, measurement volumes and sampling periods - multiple-Doppler radar and lidar measurements are both characterized by a good level of agreement with measurements performed with other reference instruments, namely sonic anemometers and a lidar profiler. Through a linear regression analysis between virtual-tower measurements, lidar profiler and sonic anemometer data, it was found that the slope is always within $0.84-1.02$, while the correlation is always larger than $R^{2}=0.87$. No system- atic bias errors have been detected for either radar or lidar measurements of the wind horizontal wind speed and direction. Regarding the vertical velocity retrieved through the triple-Doppler lidar measurements, accuracy deteriorates rapidly with reducing height along the virtual tower, which is mainly a consequence of to the lidar setup and the reduced elevation angles.

This assessment study has shown that multiple-Doppler scans performed with either scanning lidars or radars allow achieving high accuracy in the retrieval of the wind speed and wind direction. The Ka-band radars generally provide continuous radial velocity measurements out to the maximum range 
when distributed meteorological targets (water droplets, ice crystals etc.) are present. Overall, The Ka-band radar system is characterized by a higher carrier-to-noise ratio under clear-air conditions (low aerosol concentration) and during light precipitations. A limitation of Doppler radars compared to lidars is the effect of beam spread at large ranges. Indeed, for the radars a divergence angle of $0.498^{\circ}$ results in a beam spread of $17.1 \mathrm{~m}$ at $2 \mathrm{~km}$ range and $85.5 \mathrm{~m}$ at $10 \mathrm{~km}$ range. The scanning lidars, in contrast, have poor signal quality during precipitations, and the carrier-to-noise ratio strongly depends on the concentration of aerosol suspended in the atmosphere. However, lidars might have greater data availability under non-precipitation conditions and typical aerosol concentrations. The divergence angle of the lidars is practically negligible, leading to a constant spatial resolution throughout the measurement range. Regarding the scanning capabilities, the Ka-band radars have a maximum angular velocity in the scanning of $30^{\circ} \mathrm{s}^{-1}$, while for the lidars it is only $8^{\circ} \mathrm{s}^{-1}$.

Given the challenges associated with the collection of dual-Doppler radar data in non-precipitating environments, future experiments could incorporate both disdrometers and particulate monitors to better characterize clear air and precipitating environments most conducive to radar data collection. Data availability for all systems might also improve later in the calendar year when a greater concentration of scatterers is naturally present in the atmosphere.

Data availability. The data from all the instruments deployed during the XPIA field campaign are now available at DOE's Data Access Portal (DAP) located at https://a2e.pnnl.gov/data. Access to the general public has been open since 1 April 2016. In order to access the data, users need to create an account on the website given above. For further inquiries please contact either Julie Lundquist (julie.lundquist@ colorado.edu) James Wilczak (james.m.wilczak@noaa.gov).

Competing interests. The authors declare that they have no conflict of interest.

Acknowledgements. This paper was developed based upon funding from the Alliance for Sustainable Energy, LLC, Managing and Operating Contractor for the National Renewable Energy Laboratory for the U.S. Department of Energy.

Edited by: W. Shaw

Reviewed by: two anonymous referees

\section{References}

Aitken, M. L., Banta, R. M., Pichugina, Y. L., and Lundquist, J. K.: Quantifying wind turbine wake characteristics from scanning remote sensor data, J. Atmos. Ocean. Tech., 31, 765-787, 2014.
Banta, R. M., Newsom, R. K., Lundquist, J. K., Pichugina, Y. L., Coulter, R. L., and Mahrt, L.: Nocturnal low-level jet characteristics over Kansas during cases-99, Bound.-Lay. Meteorol., 105, 221-252, 2002.

Bingöl, F., Mann, J., and Foussekis, D.: Conically scanning lidar error in complex terrain, Meteor. Z., 18, 189-195, 2009.

Bonin, T. A., Blumberg, W. G., Klein, P. M., and Chilson, P. B.: Thermodynamic and turbulence characteristics of the southern great plains nocturnal boundary layer under differing turbulent regimes, Bound.-Lay. Meteorol., 157, 401-420, 2015.

Calhoun, R., Heap, R., Princevac, M., Newsom, R., Fernando, H., and Ligont, D.: Virtual towers using coherent Doppler lidar during the joint urban 2003 dispersion experiment, J. Appl. Meteorol. Clim., 45, 1116-1126, 2006.

Carbajo-Fuertes, F., Iungo, G. V., and Porté-Agel, F.: 3D turbulence measurements using three synchronous wind lidars: validation against sonic anemometry, J. Atmos. Ocean. Tech., 31, 15491556, 2014.

Cariou, J.-P.: Pulsed lidars, in: Remote Sensing for Wind Energy. Ris $\varnothing$ report Ris $\varnothing-\mathrm{I}-3184(\mathrm{EN})$, Ris $\varnothing$ National Laboratory for SustainableEnergy, edited by: Peña, A. and Hasager, C. B., Ris $\varnothing$ National Laboratory for Sustainable Energy, Technical University of Denmark, Roskilde, Denmark, 65-81, 2015.

Choukulkar, A., Brewer, W. A., Sandberg, S. P., Weickmann, A., Bonin, T. A., Hardesty, R. M., Lundquist, J. K., Delgado, R., Iungo, G. V., Ashton, R., Debnath, M., Bianco, L., Wilczak, J. M., Oncley, S., and Wolfe, D.: Evaluation of single and multiple Doppler lidar techniques to measure complex flow during the XPIA field campaign, Atmos. Meas. Tech., 10, 247-264, doi:10.5194/amt-10-247-2017, 2017.

Courtney, M., Wagner, R., and Lindelöw, P.: Testing and comparison of lidars for profile and turbulence measurements in wind energy, IOP Conf. Ser., Earth Environ. Sci., 1, 012021, doi:10.1088/1755-1307/1/1/012021, 2008.

Debnath, M., Iungo, G. V., Ashton, R., Brewer, W. A., Choukulkar, A., Delgado, R., Lundquist, J. K., Shaw, W. J., Wilczak, J. M., and Wolfe, D.: Vertical profiles of the 3-D wind velocity retrieved from multiple wind lidars performing triple range-height-indicator scans, Atmos. Meas. Tech., 10, 431-444, doi:10.5194/amt-10-431-2017, 2017.

Emeis, S., Harris, M., and Banta, R. M.: Boundary-layer anemometry by optical remote sensing for wind energy applications, Meteor. Z., 16, 337-347, 2007.

Farnet, E. C. and Stevens, G. H.: Pulse compression radar, Radar Handbook, M. I. Skolnik, McGraw-Hill, 1990.

George, R. and Yang, J.: A survey for methods of detecting aircraft vortices, Chicago, IL, 2012, in: Proc. ASME Int. Design Eng. Tech. Conf. Comp. Infor. Eng., Chicago, IL, USA, 12-15 August, 41-50, 2012.

Gunter, W. S., Schroeder, J. L., and Hirth, B. D.: Validation of Dual-Doppler Wind Profiles with in situ Anemometry, J. Atmos. Ocean. Tech., 32, 943-960, 2015.

Hill, M., R. Calhoun, Fernando, H. J. S., Wieser, A., Dornbrack, A., Weissmann, M., Mayr, G., and Newsom, R.: Coplanar Doppler lidar retrieval of rotors from T-REX, J. Atmos. Sci., 67, 713-729, 2010.

Hirth, B. D. and Schroeder, J. L.: Documenting wind speed and power deficits behind a utility-scale wind turbine, J. Appl. Meteorol. Clim., 52, 39-46, 2013. 
Hirth, B. D., Schroeder, J. L., Gunter, W. S., and Guynes, J. G.: Coupling Doppler radar-derived wind maps with operational turbine data to document wind farm complex flows, Wind Energy, 18, 529-540, 2015.

Horanyi, A., Cardinali, C., and Rennie, M.: The assimilation of horizontal line-of-sight wind information into the ECMWF data assimilation and forecasting system. Part I: the assessment of wind impact, Q. J. Roy. Meteor. Soc., 141, 1223-1232, 2015.

Iungo, G. V.: Experimental characterization of wind turbine wakes: wind tunnel tests and wind LiDAR measurements, J. Wind Eng. Ind. Aerod., 149, 35-39, 2016.

Iungo, G. V. and Porté-Agel, F.: Measurement procedures for characterization of wind turbine wakes with scanning Doppler wind LiDARs, Adv. Sci. Res., 10, 71-75, doi:10.5194/asr-10-71-2013, 2013.

Iungo, G. V. and Porté-Agel, F.: Volumetric lidar scanning of wind turbine wakes under convective and neutral atmospheric stability regimes, J. Atmos. Ocean. Tech., 31, 2035-2048, 2014.

Iungo, G. V., Wu, Y.-T., and Porté-Agel, F.: Field measurements of wind turbine wakes with lidars, J. Atmos. Ocean. Tech., 30, 274287, 2013.

Jones, G. and Bouamane, L.: Historical Trajectories and Corporate Competences in Wind Energy, Boston, MA, Harvard Business School Working Paper no. 11-112, 1-82, 2011.

Kaimal, J. C. and Gaynor, J. E.: The Boulder atmospheric observatory, J. Clim. Appl. Meteorol., 22, 863-880, 1983.

Lundquist, J. K., Churchfield, M. J., Lee, S., and Clifton, A.: Quantifying error of lidar and sodar Doppler beam swinging measurements of wind turbine wakes using computational fluid dynamics, Atmos. Meas. Tech., 8, 907-920, doi:10.5194/amt-8-9072015, 2015.

Lundquist, J. K., Wilczak, J. M., Ashton, R., Bianco, L., Brewer, W. A., Choukulkar, A., Clifton, A. J., Debnath, M., Delgado, R., Friedrich, K., Gunter, S., Hamidi, A., Iungo, G. V., Kaushik, A., Kosović, B., Langan, P., Lass, A., Lavin, E., Lee, J. C.-Y., McCaffrey, K. L., Newsom, R. K., Noone, D. C., Oncley, S. P., Quelet, P. T., Sandberg, S. P., Schroeder, J. L., Shaw, W. J., Sparling, L., Martin, C. S., Pe, A. S., Strobach, E., Tay, K., Vanderwende, B. J., Weickmann, A., Wolfe, D., and Worsnop, R.: Assessing state-of-the-art capabilities for probing the atmospheric boundary layer: the XPIA field campaign, B. Am. Meteorol. Soc., 98, 289-314, doi:10.1175/BAMS-D-15-00151.1, 2016.

Mann, J., Cariou, J.-P., Courtney, M. S., Parmantier, R., Mikkelsen, T., Wagner, R., Lindelow, P., Sjoholm, M., and Enevoldsen, K.: Comparison of 3D turbulence measurements using three staring wind lidars and a sonic anemometer, Meteorol. Z., 18, 135-140, 2009.

McCaffrey, K., Quelet, P. T., Choukulkar, A., Wilczak, J. M., Wolfe, D. E., Oncley, S. P., Brewer, W. A., Debnath, M., Ashton, R., Iungo, G. V., and Lundquist, J. K.: Identification of tower-wake distortions using sonic anemometer and lidar measurements, Atmos. Meas. Tech., 10, 393-407, doi:10.5194/amt-10-393-2017, 2017.
Mikkelsen, T., Courtney, M., Antoniou, I., and Mann, J.: Wind scanner: a full-scale laser facility for wind and turbulence measurements around large wind turbines, in: Europ. Wind Energy Conf., January 2007, Brussels, Belgium, 1, 012018, 2008.

Newsom, R., Calhoun, R., Ligon, D., and Allwine, J.: Linearly organized turbulence structures observed over a suburban area by dual-Doppler lidar, Bound.-Lay. Meteorol., 127, 111-130, 2008.

Newsom, R. K., Ligon, D., Calhoun, R., Heap, R., Cregan, E., and Princevac, M.: Retrieval of microscale wind and temperature fields from single- and dual-Doppler lidar data, J. Appl. Meteorol., 44, 1324-1345, 2005.

O'Hora, F. and Bech, J.: Improving weather radar observations using pulse-compression techniques, Meteorol. Appl., 14, 389401, 2007.

Pena, A., Hasager, C. B., Lange, J., Anger, J., Badger, M., Bingol, F., Bischoff, O., Cariou, J.-P., Dunne, F., Emeis, S., Harris, M., Hofsass, M., Karagali, I., Laks, J., Larsen, S., Mann, J., Mikkelsen, T., Pao, L. Y., Pitter, M., Rettenmeier, A., Sathe, A., Scanzani, F., Schlipf, D., Simley, E., Slinger, C., Wagner, R., and Wurth., I.: Remote sensing for wind energy, DTU Wind EnergyE-Report, 260 pp., ISBN: 978-87-93278-34-9, 2013.

Rao, I. S., Anandan, V. K., and Reddy, P. N.: Evaluation of DBS wind measurement technique in different meam configurations for a VHF wind profiler, J. Atmos. Ocean. Tech., 25, 2304-2312, 2008.

Segalini, A. and Arnqvist, J.: A spectral model for stably stratified turbulence, J. Fluid Mech., 781, 330-352, 2015.

Simley, E. and Pao, L.: LIDAR Wind Speed Measurements of Evolving Wind Fields, Tech. Rep. NREL/SR-5000-55516, National Renewable Energy Laboratory, 2012.

Simley, E., Angelou, N., Mikkelsen, T., Sjöholm, M., Mann, J., and Pao, L. Y.: Characterization of wind velocities in the upstream induction zone of a wind turbine using scanning continuous-wave lidars, J. Renew. Sustain. Energy, 8, 013301, doi:10.1063/1.4940025, 2016.

Smalikho, I. N. and Banakh, V. A.: Estimation of aircraft wake vortex parameters from data measured with a $1.5-\mu \mathrm{m}$ coherent Doppler lidar, Opt. Lett., 40, 3408-3411, 2015.

Thresher, R., Robinson, M., and Veers, P.: Wind energy technology: current status and future, Phys. Sustain. Energy Conf., University of California at Berkeley 1-2 March, 2008.

Vanderwende, B. J., Lundquist, J. K., Rhodes, M. E., Takle, E. S., and Irvin, S. L.: Observing and simulating the summertime lowlevel jet in central Iowa, Mon. Weather Rev., 143, 2319-2336, 2015.

Wilczak, J. M., Oncley, S. P., and Stage, S. A.: Sonic anemometer tilt correction algorithms, Bound.-Lay. Meteorol., 99, 127-150, 2001. 